\title{
The Effects of Perioperative Intra-aortic Balloon Counter Pulsation on Left Ventricular Function in Patients Undergoing Coronary Revascularization Surgery
}

\author{
Md. Faizus Sazzad ${ }^{1}$, Prasanta Kumar Chanda ${ }^{2}$, Farooque Ahmed ${ }^{3}$
}

\begin{abstract}
:
Intraaortic balloon pump (IABP) is the most common mechanical assist device used for the treatment of low cardiac output in patients undergoing coronary artery bypass grafting (CABG). Despite recent advancement in cardiac surgery the overall mortality in patients receiving perioperative IABP remains high. In most cases the patient has poor Left ventricular (LV) function, diastolic dysfunction, recent myocardial infarction with septal rupture, heart failure and/or cardiogenic shock receiving an IABP counterpulsation support. Unfortunately patients with preserved LV function may also require IABP support to wean from cardio pulmonary bypass due to post-surgical myocardial dysfunction.
\end{abstract}

This hospital-based prospective observational study evaluated 60 patients, who underwent CABG, divided into two groups. Left ventricular ejection fraction was
$56.93 \pm 7.666$ in Group A compared to $41.50 \pm 6.735$ in Group B. When compared with the corresponding preoperative ejection fraction both the group found to have improved ejection fraction among the survivors at three months. Left ventricular end diastolic diameter and end systolic diameter was also found improved in both the groups $(53.15 \pm 3.231 \mathrm{~mm}$ vs $59.47 \pm$ $4.200 \mathrm{~mm}$ and $41.52 \pm 2.847 \mathrm{~mm}$ vs $44.47 \pm 3.636 \mathrm{~mm}$ respectively). No significant difference was observed in terms of 30 days mortality and postoperative outcome.

Given its survival benefit, surgeons must use IABP in a pre-planned way. Here by we recommend that the use of risk prediction score for patient undergoing coronary revascularization surgery is useful.

Key Words: Aorta, Counter Pulsation, Coronary Artery Bypass Grafting.

(Bangladesh Heart Journal 2017; 32(2) : 94-99)

Introduction

Intraaortic balloon pump (IABP) is the most common mechanical assist device used for the treatment of low

1. Associate Consultant, Department of Cardiac Surgery, Ibrahim Cardiac Hospital \& Research Institute, Dhaka, Bangladesh.

2. Associate Professor \& Senior Consultant, Department of Cardiac Surgery, National Heart Foundation Hospital \& Research Institute, Dhaka, Bangladesh.

3. Professor \&Chief Cardiac Surgeon, Department of Cardiac Surgery, National Heart Foundation Hospital \& Research Institute, Dhaka, Bangladesh.

Address of Correspondence: Dr Md. Faizus Sazzad,, Associate Consultant, Department of Cardiac Surgery, Ibrahim Cardiac Hospital \& Research Institute, 122, Kazi Nazrul Islam Avenue, Shahbag, Dhaka1000, Bangladesh. Cell Phone: +8801727210741 , Email: mfsazzad@gmail.com cardiac output in patients undergoing coronary artery bypass grafting (CABG). The counterpulsation theory was described by Harken in 1958 which lead to the first introduction of IntraAortic Balloon Pump (IABP) in 1968 by Kantrowiz group ${ }^{1,2}$. The use of balloon pumps increased substantially from 1968 to $1995^{3-5}$, and IABP use increased progressively in patients who experienced difficult weaning from cardiopulmonary bypass (CPB) 6,7 .

IABP successfully increase coronary artery blood ûow during diastole by inûating, and decrease the workload of the heart by deûating just before systole, thus reducing afterload $^{8}$. LV volume and LV end-diastolic pressure (EDP) have been demonstrated to decrease in patients treated

DOI: http://dx.doi.org/10.3329/bhj.v32i2.36095

Copyright $\odot 2017$ Bangladesh Cardiac Society. Published by Bangladesh Cardiac Society. This is an Open Access articles published under the Creative Commons Attribution-NonCommercial 4.0 International License (CC BY-NC). This license permits use, distribution and reproduction in any medium, provided the original work is properly cited and is not used for commercial purposes. 
with IABP, whereas cardiac output, ejection fraction (EF), and coronary ûow may increase $\mathrm{e}^{9-11}$.

The LV performance is one of the most important predictor of CABG outcome. In most cases the patient with poor Left ventricular (LV) function is receiving an IABP counterpulsation support. Acute volume load applied during contraction or relaxation phase in heart muscle, increases or decreases the ejection phase duration, respectively. Moreover, altered loading conditions may result in dyssynchronous relaxation of the LV12-13.

Myocardial relaxation is known to be sensitive to afterload and to LV-dyssynchrony in patients with dilated cardiomyopathy ${ }^{14}$. LV mechanical dyssynchrony in these patients decreased due to reduction in wall stress induced by interventions such as vasodilators, cardiomyoplasty, or LV ventricular reduction surgery. Hence IABP in patients with low EF may considerably inûuence cardiac performance by acute afterload changes and concomitant changes in LV mechanical dyssynchrony.

Unfortunately patients with preserved LV function may require IABP support for a number of factors e.g. advanced age, female sex, left main stenosis, redo operation, recent myocardial infarction and difficult to wean from cardio pulmonary bypass due to post-surgical myocardial dysfunction. However, overall mortality in patients receiving intraoperative or postoperative IABP remains high, ranging from $27 \%$ to $52 \%{ }^{15}$. The survivors, irrespective of their preoperative LV performance are shown altogether to have a better outcome in postoperative periods in most of the studies.

Some prospective randomized and observational studies suggest that preoperative IABP insertion in high-risk patients undergoing $C A B G$ decreases mortality and morbidity, and shortens postoperative hospital length of stay ${ }^{16,17}$. But insertion practices vary, with the Benchmark Registry and Society of Thoracic Surgeons database and hence the role of the preoperative prophylactic IABP is subject to debate ${ }^{18}$.

Thus the conflict persists in issue concerning the timing of IABP insertion and identification of appropriate candidacy for IABP. Although the outcome of IABP in patients with poor LV function is documented well, no comprehensive study showed the outcome for preserved LV function group. To the best of our knowledge, there has been no study done so far in Bangladesh regarding the IABP outcome in CABG patients. Therefore it seems logical to investigate. Accordingly, we sought to identify the outcome of patients receiving IABP support by concentrating upon LV performance.

\section{Materials \&Methods}

This study was a hospital-based prospective observational study andwas conducted in the Department of Cardiac Surgery, National Heart Foundation Hospital and Research Institute, Dhaka, Bangladesh from July 2013 to June 2014 (1 year). Data collected from all patients who underwent elective or emergency Coronary artery bypass grafting (CABG) surgeryrequiring IABP support perioperatively. Patients were excluded from the study who has renal dysfunction (Creatinine>2.0 mg/dl), acute or chronic pulmonary disease, associated valvular heart disease, or associated congenital cardiac anomaly; requiring coronary end-arterectomy and/or Re-do coronary artery bypass grafting. Sample size was calculated using the mean difference of EDP (End diastolic pressure) to evaluate LV performance in patients with IABP with low ejection fraction, reported by Schreuder et al., $2005^{19}$.

A prognostic risk stratiûcation model (Table-1) to predict the need for IABP insertion in patients undergoing CABG proposed by Antonio Miceliet $\mathrm{al}^{20}$ in 2010 was used to evaluate its usefulness. All the patients are prospectively allocated into two groups. Group A: Constitute patients with preserved LV, Group B: Constitute patients with poor LV function.

A 5-MHz phased-array transesophageal transducer (GE: Healthcare Vivid-7 pro) was used for Transesophageal Echocadiography to measure left ventricle ejection fraction (EF) both prebypass and postbypass states. A trans-thoracic echocardiography was done on second post-operative day, during discharge, at all the followup of the patient with GE: Vivid 7-pro. Trans-thoracic echocardiography was done by Non-invasive Echocardiography consultants of NHFH\&RI blinded towards the study.

Biochemical markers; Troponin-I and NT-proBNP analysis were done with Siemens Stratus CS Acute Care Diagnostic System; Flurometric analyser. A single data of each was documented and the highest value of these results was taken if repeated test were done. All the biochemical tests were done at the Department of Biochemistry at NHFH\&RI.

Keeping compliance with Helsinki Declaration for Medical Research Involving Human Subjects 1964, all patients were informed verbally about the study design, the purpose of the study, and right of the participants to withdraw themselves from the project, at any time for any reason. Written consent was obtained from each subject in a pre-formed consent paper which was written in easily understandable local language. The study was approved by Ethical review committee of NHFH\&RI and due clearance was obtained.The study was commenced following acceptance of the protocol by BCPS. Data were processed using 
software SPSS (Statistical Package for Social Sciences) version 16.0 and for all analytical tests, the level of significance was set at 0.05 and $p<0.05$ was considered significant.

\section{Results}

The present study performed in NHFH\&RI, Dhaka, included 60 patients divided into 2 groups. The age ranged from 35 years to 67 years, but mean ages of the Group Aand Group B was $53.21 \pm 6.66$ and $52.97 \pm 7.77$ respectively. Although a male preponderance was observed in both groups, the difference between the groups with respect to sex was not evident (Fig-1). Both the groups were identical in respect of height, weight, BMI and BSA. Distribution of overweight and obese patients was almost equal in both groups.

Figure 1 shows the sex distribution of the patients. Out of 60 patients, male was predominant $60.7 \%$ in Group A, $71.9 \%$ in Group B. The two groups' difference was not statistically significant by Fisher's Exact Test $(p=0.261)$.

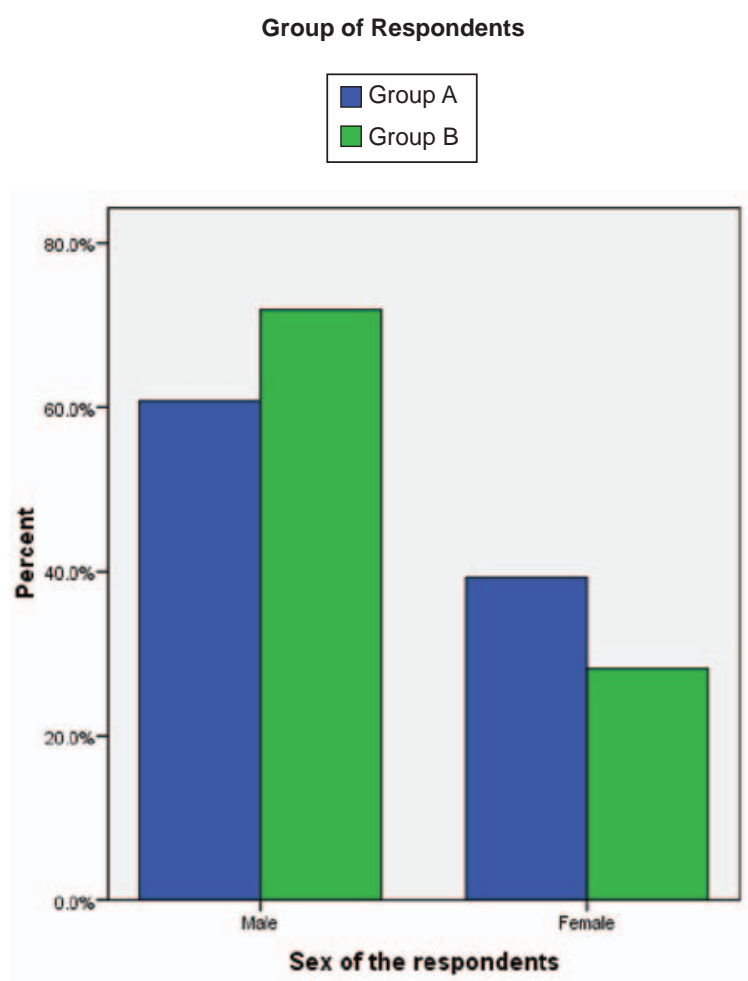

Fig.-1: Sex distribution of the study patients

The risk factors for ischemic heart disease like Diabetes was sub-classed in to Non diabetic, Diet control diabetes, Oral pills and insulin controlled diabetes. The difference between two groups was not statistically significant. Other cardiac risk factors included Hypertension, Hyperlipidemia
Table-I

IABP Risk Score Calculator

\begin{tabular}{lc}
\hline Variable & Risk Score \\
\hline Age $>70$ years & 2 \\
CCS $3-4$ class & 2 \\
Previous cardiac surgery & 3 \\
Moderate EF $>40 \%$ & 2 \\
Poor EF $<40 \%$ & 7 \\
Interval Between MI and Surgery (<30 days) & 2 \\
Left main stem disease $(>50 \%)$ & 2 \\
Emergency surgery & 3 \\
\hline
\end{tabular}

CCS = Canadian Cardiovascular Society; EF = ejection fraction; $\mathrm{MI}=$ myocardial infarction. High-risk (score >14), Medium-risk (score 7 to 13), and Low-risk group (score <6) proposed by Miceli et al 20

and Smoking habit etc is delineated in Table-2. Other clinical characteristics which has potential influence in the outcome of coronary artery bypass surgery were also evaluted.

The extent of coronary artery disease was similar in both the groups and most of the patients were having triple vessel disease. A large number of patients in both the groups had Left main coronary artery disease $57.1 \%$ and $40.6 \%$ respectively. In regards to Echocardiography findings; there was no significant difference in both groups in terms of LVEF and left ventricular end diastolic diameter.However, Group A and Group B showed left ventricular end systolic diameter $39.25 \pm 3.329$ vs $45.53 \pm 5.061$ which was statistically significant $(p=0.013)$. Regional wall motion abnormality was also found statistically significant in between Group Aand Group B; these are expected in patients with low ejection fraction.

Operative urgency is an important predictor of coronary revascularization surgery. In our study we found emergency surgery was 25\% in Group A and 18.8\% in Group B; Urgent surgery was $39.3 \%$ and $40.6 \%$ respectively and rest were elective cases. The distribution was statistically not significant in all cases. All patients were assessed by using Euroscore-Il and Logistic Euroscore, no statistical difference was found.

Intra-aortic balloon pump is used in peri-operative period as per hospital protocol and by using IABP-score. We evaluated the insertion of IABP in pre, per and post-operative periods. $46.4 \%$ patients received IABP in Group Ain preoprative period than that of $50 \%$ of the patients of Group B. In all perioperative period the use of IABP in both the groups were statistically non significant.

The post-operative out come between the groups was equivocal (Table-3). Other post operative complication 
Table-II

Risk factors comparison of the study

\begin{tabular}{|c|c|c|c|}
\hline Risk factors & $\begin{array}{c}\text { Group-A } \\
(n=28)\end{array}$ & $\begin{array}{c}\text { Group-B } \\
(n=32)\end{array}$ & $P$ value \\
\hline a No DM & $8(28.6)$ & $13(40.6)$ & $0.740^{\mathrm{NS}}$ \\
\hline${ }^{\mathrm{b}}$ Diet Control & $3(10.7)$ & $2(6.2)$ & \\
\hline b Oral & $10(35.7)$ & $11(34.4)$ & \\
\hline b/nsulin & $7(25)$ & $6(18.8)$ & \\
\hline a HTN & $25(89.3)$ & $29(90.6)$ & $0.863^{\mathrm{NS}}$ \\
\hline a HDL & $22(78.6)$ & $25(78.1)$ & $0.967^{N S}$ \\
\hline aNon Smoker & $16(57.1)$ & $18(56.2)$ & $0.838^{\mathrm{NS}}$ \\
\hline${ }^{b}$ Current smoker & $3(10.7)$ & $5(15.6)$ & \\
\hline${ }^{b}$ Ex-smoker & $9(32.1)$ & $9(28.1)$ & \\
\hline${ }^{a}$ Angina Status & $22(78.7)$ & $26(81.3)$ & $0.495^{\mathrm{NS}}$ \\
\hline${ }^{b}$ Unstable & $13(46.6)$ & $11(34.4)$ & \\
\hline${ }^{b}$ Stable & $9(32.1)$ & $15(46.9)$ & \\
\hline a Family History & $4(14.3)$ & $2(6.5)$ & $0.320^{\mathrm{NS}}$ \\
\hline${ }^{a} \mathrm{pHTN}$ & $6(21.4)$ & $17(53.1)$ & $0.039^{S}$ \\
\hline${ }^{\mathrm{a} C L D}$ & $1(3.6)$ & $1(3.1)$ & $0.923^{N S}$ \\
\hline aPVD & $1(3.6)$ & $5(6.77)$ & $0.121^{N S}$ \\
\hline a Extra cardiac arteriopathy & $0(0)$ & $1(3.1)$ & $0.698^{\mathrm{NS}}$ \\
\hline apoor mobility & $1(3.33)$ & $0(0)$ & $0.346^{\mathrm{NS}}$ \\
\hline aNeurological dysfunction & $0(0)$ & $1(3.1)$ & $0.346^{\mathrm{NS}}$ \\
\hline${ }^{\mathrm{a} C V D}$ & $4(14.3)$ & $8(25)$ & $0.301^{N S}$ \\
\hline aprevious $\mathrm{PCl}$ & $3(10.7)$ & $5(15.6)$ & $0.577^{\mathrm{NS}}$ \\
\hline${ }^{\mathrm{a} C}$ ardiogenic shock & $3(10.7)$ & $2(6.2)$ & $0.533^{\mathrm{NS}}$ \\
\hline a $\mathrm{Ml}$ & $28(100)$ & $32(100)$ & $0.168^{\mathrm{NS}}$ \\
\hline${ }^{b} \mathrm{MI} 6-24 \mathrm{Hr}$ & $4(14.3)$ & $2(6.2)$ & \\
\hline bMI $1-30$ days & $16(57.1)$ & $16(50)$ & \\
\hline bMI 31-90 days & $5(17.8)$ & $7(21.9)$ & \\
\hline${ }^{b} \mathrm{MI}>90$ days & $3(10.7)$ & $7(21.9)$ & \\
\hline
\end{tabular}

aData were analysed using Chi-Square $\left(c^{2}\right)$ Test and level of significance was 0.05 . Figures in the parentheses denote corresponding percentage. bata showing subclass analysis. ( $n=$ number of patients, NS= Not significant, DM=Diabetes Mellitus, $\mathrm{HTN}=$ Hypertension, $\mathrm{HDL}=$ Hyperlipidaemia, $\mathrm{pHTN}=$ Pulmonary hypertension, $\mathrm{CLD}=$ Chronic liver disease, $\mathrm{PVD}=$ peripheral vascular disease, $C V D=C e r e b r o$ Vascular disease, $\mathrm{PCl}=$ percutaneous coronary intervention, $\mathrm{Ml}=$ myocardial Infarction)
Table-III

Post operative outcome variables

\begin{tabular}{lccc}
\hline Characteristics & $\begin{array}{c}\text { Group-A } \\
(\mathrm{n}=28)\end{array}$ & $\begin{array}{c}\text { Group-B } \\
(\mathrm{n}=32)\end{array}$ & P value \\
\hline "No of Distal anastomoses & $3.36 \pm 0.138$ & $3.28 \pm 0.144$ & $0.626^{\mathrm{NS}}$ \\
\#Ventilation (Hr) & $24.46 \pm 6.064$ & $30.25 \pm 10.491$ & $0.652^{\mathrm{NS}}$ \\
\#Total ICU stay (Hr) & $48.93 \pm 7.676$ & $79.75 \pm 17.924$ & $0.203^{\mathrm{NS}}$ \\
"Total Step Down stay (Hr) & $37.64 \pm 3.622$ & $33.88 \pm 4.006$ & $0.193^{\mathrm{NS}}$ \\
"Pre-op stay (Days) & $4.11 \pm 0.772$ & $3.81 \pm 1.048$ & $0.361^{\mathrm{NS}}$ \\
\#Post-op stay (Days) & $10.82 \pm 1.844$ & $17.62 \pm 2.065$ & $0.056^{\mathrm{NS}}$ \\
\#Total Hospital stay (Days) & $14.93 \pm 1.858$ & $21.44 \pm 2.472$ & $0.037^{\mathrm{S}}$ \\
a Reopening & $1(3.6)$ & $1(3.1)$ & $0.923^{\mathrm{NS}}$ \\
a Extubation (<24Hr) & $24(85.7)$ & $27(84.4)$ & $0.885^{\mathrm{NS}}$ \\
a Reintubation & $2(7.1)$ & $1(3.4)$ & $0.532^{\mathrm{NS}}$ \\
a Status at 30 days (alive) & $26(92.9)$ & $30(93.8)$ & $0.890^{\mathrm{NS}}$ \\
a Readmission (90 days) & $6(21.4)$ & $5(15.6)$ & $0.562^{\mathrm{NS}}$ \\
\#Ejection fraction(3 months) & $56.93 \pm 7.666$ & $41.50 \pm 6.735$ & $0.621^{\mathrm{NS}}$ \\
\# LVIDd (mm) (3 months) & $53.15 \pm 3.231$ & $59.47 \pm 4.200$ & $0.146^{\mathrm{NS}}$ \\
\#LVIDs (mm) (3 months) & $41.52 \pm 2.847$ & $44.47 \pm 3.636$ & $0.089^{\mathrm{NS}}$ \\
a NT-proBNP (Highest value) & $8(28.6)$ & $7(21.9)$ & $0.550^{\mathrm{NS}}$ \\
a Troponin-I (Highest value) & $5(17.9)$ & $5(15.6)$ & $0.817^{\mathrm{NS}}$ \\
a RWMA (3 months) & $10(40.7)$ & $4(13.3)$ & $0.001^{\mathrm{s}}$ \\
a TVI (3 months) & $2(7.7)$ & $3(6.9)$ & $0.910^{\mathrm{NS}}$ \\
a CFM (3 months) & $3(11.5)$ & $4(10.3)$ & $0.887^{\mathrm{NS}}$ \\
\hline & & & \\
\hline
\end{tabular}

\# Data were analysed using Student's t-Test. ${ }^{\text {a }}$ Data were analysed using Chi-Square $\left(\mathrm{c}^{2}\right)$ Test. Level of significance was 0.05. Figures in the parentheses denote corresponding percentage. $(n=$ number of patients, $S=$ Significant, NS= Not significant, LVIDd= Left ventricular end diastolic diameter, LVIDs= Left ventricular end systolic diameter, RWMA= Regional wall motion abnormality, TVI= Tissue velocity index, CFM= Colour flow mapping

including renal failure and arrythmia were equally high in both the groups $(p=0.673)$. Although the rate of morbidity was higher in both the groups the status of the patients at 30 days was found better.

\section{Discussion}

The present study was designed to compare the LV function for highly selective group of patients undergoing coronary revascularization surgery to find the answer of the research question "Preserved LV function shows better outcome with Intra-aortic balloon counter pulsation therapy". We matched the pre-operative clinical characteristics of both the groups apart from Echocardiographic LV function parameters. Clinical characteristics which has potential influence in the outcome of coronary artery bypass surgery were evaluted 
and found similar to the studies reported by Torchiana ${ }^{3}$ et al, Barron ${ }^{4}$ et al,Sanfelippo ${ }^{11}$ et al.Accordingly, the effort in this study was to find out difference in IABP outcome in preserved and poor LV function group at coronary revascularization surgery.

We extensively studied the left ventricular function and evaluated both the groups with a number of post-operative chemical biomarker. NTproBNP, which is a strong biomarker for heart failure has been evaluated in both the groups. Comparison of highest recorded value was high in $28.6 \%$ patient in Group Aand $21.9 \%$ in Group B ( $p=0.550)$. TroponinI was also recorded in a similar fashion as NTproBNP. Post operative 2D Echocardiography (within 3 months at follow up) was done in all surviours to assess regional wall motion abnormality, Tissue velocity index and color flow mapping by using GE Vivid Pro- $7^{\mathrm{R}}$. No significant difference been observed between the groups. RWMA showed significant differnce between the groups. A significant improvement noted in Group B, which justifies well known benefit of coronary revascularizarion.

Duration of hospital stay among the survivors was $14.93 \pm$ 1.858 days vs $21.44 \pm 2.472$ which was statistically significant. Similar results been demonstrated in randomized trials, reported by Ohmanet $\mathrm{al}^{8}$. Apart from this all other perioperative outcome variables were non-significant between the groups when compared to other published reports. Overall mortality in patients receiving intraoperative or postoperative IABP reported Baskettet al in 2002 was higher than our result ${ }^{15}$. About $93 \%$ patients of Group A were alive at 30 days in comparison with $93.8 \%$ of Group B (Table-3).

This is a single centre non-randomized study. A multivariate regression analysis was not done, which we believe could be useful to verify the profound cause-effect-outcome. We applied blinding (The Echocardigraphers were blinded towards the grouping) but the sample sizewas small due to short duration (1year)and non-funded post-graduation study oriented research.

\section{Conclusion}

This study shows that, use of IABP in preserved LV function patients does not show any survival benefit at 30 days and no difference in outcome in terms of LVEF, LVIDd, and LVIDs when measured with TVI and CFM.The results of this study and discussion thereof prompt us to recommend that there is no significant advantage in terms of LV function in patients with coronary revascularization requiring IABP.

Intra-aortic balloon pump is a life-saving assist device and its use should be considered in myocardial revascularization surgery, when indicated. Ajudicious use of IABP is life saving and need to preserve its use for the appropriate cases. Given its survival benefit, surgeons must use IABP in a pre-planned way. Here by the recommendation is the use of risk prediction scorefor patient undergoing coronary revascularization surgery is useful.

\section{References}

1. Kantrowitz A, Tjonneland S, Freed PS, et al. Initial clinicalexperience with intra-aortic balloon pumping in cardiogenic shock.JAMA 1968;203:113-118.

2. Willerson JT, Curry GC, Watson JT, et al. Intra-aortic balloon counterpulsation in patients in cardiogenic shock, medically refractoryleft ventricular failure and/ or recurrent ventricular tachycardia. Am J Med 1975;58:183-191.

3. Torchiana DF, Hirsch G, Buckley MJ, et al. Intra-aortic balloonpumping for cardiac support: Trends in practice and outcome, 1968 to1995. J ThoracCardiovascSurg 1997; 113:758-769.

4. Barron HV, Every NR, Parsons LS, et al. The use of intra-aorticballoon counter-pulsation in patients with cardiogenic shock complicating acute myocardial infarction: Data from the National Registry ofMyocardial Infarction-2. Am Heart J 2001;141:933-939.

5. Stone GW, Ohman EM, Miller MF, et al. Contemporary utilization and outcomes of intra-aortic balloon counterpulsation in acutemyocardial infarction: The Benchmark Registry. J Am CollCardiol 2003;41:19401945,.

6. Gutnger DE, Ott RA, Miller M, et al. Aggressive preoperative use of intra-aortic balloon pump in elderly patients undergoing coronary artery bypass grafting. Ann ThoracSurg 1999:67;610-613.

7. Baskett RJ, O'Connor GT, Hirsch GM, et al, Northern NewEngland Cardiovascular Disease Study Group: A multicenter comparison of intra-aortic balloon pump utilization in isolated coronary arterybypass graft surgery. Ann Thorac Surg 2003;76:1988-1992,.

8. Ohman EM, George BS, White CJ, et al. Use of aortic counter-pulsation to improve sustained coronary artery patency during acute myocardial infarction: Results of a randomized trial. Circulation 1994;90:792-799.

9. Cheung AT, Savino JS, Weiss SJ: Beat-to-beat augmentationof left ventricular function by intra aortic counter pulsation. Anesthesiology 1996;84:545-54.

10. Ghali WA, AshAS, Hall RE, et al. Variation in hospital rates of intra-aortic balloon pump use in coronary artery bypass operations. Ann Thorac Surg 1999;67: 441-445. 
11. Sanfelippo PM, Baker NH, Ewy HG, et al:Experience withintra-aortic balloon counter-pulsation. Ann Thorac Surg 1986;41:36-41,

12. Downing TP, Miller DC, Stinson EB, et al:Therapeuticefficacy of intra-aortic balloon pump counter-pulsation, Analysis with concurrent "control" subjects. Circulation 1981;64(II):108-13.

13. Gillebert TC, Sys SU, Brutsaert DL et al. Inûuence of loadingpatterns on peak length-tension relation and on relaxation incardiac muscle. J Am Coll Cardiol 1989;13:483-90.

14. Hayashida W, Kumada T, Kohno F, et al. Left ventricularrelaxation in dilated cardiomyopathy: relation to loadingconditions and regional nonuniformity. J Am Coll Cardiol 1992;20:1082-91.

15. Baskett RJF, GhaliWA,Maitland A, et al. The intra-aortic balloon pump in cardiac surgery. Ann Thorac Surg 2002;74:1276-87.

16. Christenson JT, Schmuziger M, Simonet F, et al. Effective surgical management of high-risk coronary patients using preoperative intra-aortic balloon counter-pulsation therapy. Cardiovasc Surg 2001;9:383-90.

17. Field ML, Rengarajan A, Khan O, et al. Preoperative intra aortic balloon pumps in patients undergoingcoronary artery bypass grafting. Cochrane Database Syst Rev 2007;24:CD004472.

18. Lavana JD,Fraser JF,Smith SE, et al:Inûuence of timing of intra-aortic balloon placement in cardiacsurgical patients. J Thorac Cardiovasc Surg 2010;140:80-5.

19. Schreuder JJ, Castiglioni A, Maisano F et al. Acute decrease of left ventricular mechanical dyssynchrony and improvement of contractile state and energy efficiency after left ventricular restoration. J Thorac Cardiovascular Surg 2005;129: 138-45.

20. Miceli A, Duggan SMJ, Capoun R, et al. A clinical score to predict the need for intraaorticballoon pump in patients undergoing coronaryartery bypass grafting. Ann ThoracSurg 2010;90:522-7. 